\title{
Thermal and Mechanical Properties of Oriented Polyethylene Treated with Nitric Acid
}

\author{
Rosario Trilla, Jose M. Pereña, and Jose G. Fatou \\ U. E. I. Fisicoquímica y Física de Polímeros, \\ Instituto de Plásticos y Caucho C. S. I. C., \\ Juan de la Cierva, 3, Madrid-6, Spain
}

(Received January 21, 1983)

\begin{abstract}
Filaments of linear polyethylene stretched at different draw ratio were immersed in fuming nitric acid for periods of time ranging from 0 to $7 \mathrm{~h}$. Analysis of the groups formed was carried out by IR spectroscopy. The presence of nitrite groups at the early stages of nitration was found for the first time. However the samples did not show any weight loss, but a limited change in molecular weight. Changes in thermal properties and dynamic mechanical' relaxation were also studied. Moreover, shrinkage stress which developed when the filaments were heated under fixed ends showed a steady decrease with etching time. At $7 \mathrm{~h}$, the shrinkage stress decreased to a value similar to that produced by annealing for one hour.

KEY WORDS Polyethylene / Drawn Polymers / Nitric Acid Etching / IR Analysis / Thermal Properties / Viscoelastic Relaxation / Shrinkage Stress /
\end{abstract}

The study of the microstructure of polyethylene by selective chemical reactions has been pursued by a number of authors. Oxidative degradation with nitric acid was one of the first methods used on bulk crystallized materials and on single crystals. ${ }^{1-8}$ The general interpretation of data is based on the fact that preferential attack takes place in the noncrystalline regions and the impenetrability of the crystal lattice allows only attack to the surface. This attack causes an important weight loss, a decrease in molecular weight and changes in thermal and mechanical properties.

The morphology of drawn polymers was also investigated extensively. ${ }^{9-11}$ The structure of these systems is formed by crystalline-noncrystalline layers, found together by interconnecting chains traversing the amorphous areas. ${ }^{12}$ Fuming nitric acid preferentially attacks these areas, causing considerable weight loss. The influence of the etching temperature, time of attack and sample orientation is very important. Experiments have generally been carried out for relatively long periods of time, with total degradation of the amorphous layers.

In these investigation, two samples of linear polyethylene differing in molecular weight and oriented at different draw ratios, were exposed to fuming nitric acid for short periods of time. The experimental conditions made possible determination of the reaction steps through analysis of the groups formed and analysis of the changes in molecular weight, density, heat of melting, and mechanical properties.

\section{EXPERIMENTAL}

\section{Materials}

Two linear polyethylenes (Marlex 6003 and Marlex 6009, Philips Pe. Co.) were investigated. The number average molecular weights of these samples were $1.34 \times 10^{5}$ and $1.27 \times 10^{5}$, respectively. The polydispersities, determined by GPC, correspond to 8.5 and 12.5 .

Two samples were used. First, filaments were obtained by extrusion, using conventional drawing and anealing baths at $95^{\circ} \mathrm{C}$. Portions with draw ratios $\lambda=l / l_{0}=6,8$ and 10 were cut out. In another set of experiments, the polymer was compression molded at $160^{\circ} \mathrm{C}$ in the form of very thin sheets.

\section{Etching}

The samples were immersed in fuming nitric acid at $70^{\circ} \mathrm{C}$ in sealed Pyrex tubes in a very large excess 
of acid. The reaction time varied from 1 and $8 \mathrm{~h}$. After treatment, the samples were washed in water, rinsed with acetone in a Soxhlet for $5 \mathrm{~h}$ and finally dried in vacuum at room temperature.

\section{Characterization Methods}

Intrinsic viscosities of the samples were obtained from the usual plots, using decaline at $135^{\circ} \mathrm{C}$ as the solvent in a modified Ubbelohde Viscometer previously described. ${ }^{13}$ From the intrinsic viscosities the molecular weights were calculated using the equation $[\eta]=6.77 \times 10^{-4} \mathrm{M}^{0.67} .^{14}$

Sample densities were measured in a density gradient columm, at $23^{\circ} \mathrm{C}$, made with two nonsolvents, ethanol-water and standardized with glass beads of known density $\left( \pm 0.0001 \mathrm{~g} \mathrm{~cm}^{-3}\right)$. The density values obtained were related to crystallinities in the usual manner.

For the calorimetric study, a Perkin-Elmer D S C B-1 was used, at a heating rate of $8^{\circ} \mathrm{C} \mathrm{min}^{-1}$. It was previously calibrated with indium.

The IR study was carried out in a Perkin-Elmer 457 spectrophotometer. The $\mathrm{KBr}$ method was used, dissolving the samples in xylene and precipitating the polymer. The polymer was ground into fine powder with $\mathrm{KBr}$ and compressed into a disk. In other experiments, the films were used directly in the spectrophotometer. The base line in the IR spectra was drawn tangent to the transmission curve from 1800 to $600 \mathrm{~cm}^{-1}$.

Viscoelastic relaxation of polyethylene filaments were studied using a Rheovibron DDV II B dynamic viscoelastometer. The complex modulus, $E^{*}$, and the loss tangent, $\tan \delta$, were determined at 110 , 35,11 and $3.5 \mathrm{~Hz}$ in the temperature range between -150 and $100^{\circ} \mathrm{C}$.

Shrinkage stress was measured with an apparatus similar to that previously described. ${ }^{15}$ It had two arms, one connected to a transducer and the other halffixed to set the specimen just taut. The sample was immersed in a thermostated silicone oil bath and the transducer output was recorded as a function of time.

Specimen sections were slighlty elliptical (eccentricity less than 0.61 ) and their values were calculated by three methods: optical microscopy, weight and micrometer measurements.

\section{RESULTS AND DISCUSSION}

\section{Weight Loss and Molecular Weight Changes}

Analysis of weight loss in the oriented samples and films for short periods of time (maximum 8 hours) shows that there is no apparent weight loss. This is quite different from previous results ${ }^{8-10}$ where important weight losses were found at the beginning of the reactions. Meinel and Peterlin ${ }^{10}$ found weight losses in draw annealed as well as unannealed samples, with weight loss curves which were linear in the first part of the nitric acid attack, with loss rates of $1 \%$ per hour.

Blundell et al. ${ }^{5}$ showed the nitric acid attack to consist of phase affecting the basal and side surfaces and a negative loss due to the addition of heavy groups. However, our results showed no negative loss, probably due to differences in the samples and the compactness of the material.

During treatment, the samples underwent a limited change in molecular weight, from $.1 \times 10^{5}$ to $5.5 \times 10^{4}$, which is much lower than that observed by other authors ${ }^{10}$ probably due to the narrower molecular distribution of samples used in this work.

\section{Analysis of Groups Formed during the Reaction}

Before considering the degradation reaction with nitric acid, the oxidative agent should be defined since it was composed of nitric acid and nitrogen oxides. The pure nitric acid is dissociated as

$$
\begin{aligned}
& 2 \mathrm{HNO}_{3} \rightarrow \mathrm{H}_{2} \mathrm{O}+\mathrm{N}_{2} \mathrm{O}_{5} \\
& 2 \mathrm{~N}_{2} \mathrm{O}_{5} \rightarrow 2 \mathrm{~N}_{2} \mathrm{O}_{4}+\mathrm{O}_{2}
\end{aligned}
$$

Although nitration of aromatic hydrocarbons has been exhaustively studied, that of aliphatic hydrocarbons has been studied in the past few years in the vapor phase. The initiation process and radical mechanism have been postulated ${ }^{16}$ under experimental conditions which are more severe than in the etching process. Probably, nitric acid is dissociated into hydroxyl and nitro radicals, which are very reactive and capable of attacking hydrocarbons to form radicals. Nitric acid and nitrogen dioxide are the active agents of the $\mathrm{NO}_{2}$ radicals.

For nitrations with $\mathrm{N}_{2} \mathrm{O}_{5}$ the mechanism is as follows:

$$
\mathrm{N}_{2} \mathrm{O}_{5} \rightleftarrows \cdot \mathrm{NO}_{2}+\cdot \mathrm{NO}_{3}
$$




$$
\mathrm{RH}+\cdot \mathrm{NO}_{3} \rightarrow \cdot \mathrm{R}+\mathrm{HNO}_{3}
$$

- $\mathrm{R}$ radicals react with $\mathrm{N}_{2} \mathrm{O}_{5}$ to produce nitroderivatives or nitrate and nitrites. The nitrites are further oxidized to nitroderivatives or carboxylic acids.

Moreover, $\mathrm{N}_{2} \mathrm{O}_{4}$ may act as follows:

$$
\cdot \mathrm{R}+\mathrm{N}_{2} \mathrm{O}_{4} \rightarrow \mathrm{RONO}+\cdot \mathrm{NO}_{2}
$$

and the favourable oxidative process with $\mathrm{O}_{2}$ is given as

$$
\mathrm{R}-\mathrm{CH}_{2}-\mathrm{CH}_{2}-\mathrm{R}^{\prime}+\mathrm{O}_{2} \rightarrow \underset{\mathrm{OOH}}{\mathrm{R}-\mathrm{CH}-\mathrm{CH}_{2}-\mathrm{R}^{\prime}}
$$

to produce decomposable hydroperoxides

$$
\begin{aligned}
& \underset{\mathrm{O}}{\mathrm{R}-\mathrm{CH}}-\mathrm{CH}_{2}-\mathrm{R}^{\prime} \rightarrow \underset{!}{\mathrm{R}}-\underset{\mathrm{CH}}{\mathrm{C}}-\mathrm{CH}_{2}-\mathrm{R}^{\prime}+\cdot \mathrm{OH} \rightarrow \\
& \rightarrow \stackrel{\mathrm{O}}{\stackrel{\mathrm{C}}{\mathrm{C}} \mathrm{H}}+\cdot \mathrm{CH}_{2}-\mathrm{R}^{\prime}
\end{aligned}
$$

or

$$
\begin{aligned}
& \mathrm{R}-\mathrm{CH}-\mathrm{CH}_{2}-\mathrm{R}^{\prime}+\mathrm{R}-\mathrm{CH}_{2}-\mathrm{CH}_{2}-\mathrm{R}^{\prime} \rightarrow \\
& \quad \mathrm{O} \cdot \\
& \rightarrow \underset{!}{\mathrm{R}-\mathrm{CH}-\mathrm{CH}_{2}-\mathrm{R}^{\prime}+\mathrm{R}-\dot{\mathrm{C}} \mathrm{H}-\mathrm{CH}_{2}-\mathrm{R}^{\prime}} \\
& \quad \mathrm{OH}
\end{aligned}
$$

On the basis of these reaction, it may be reasonable to say that the formation of aldehydes and ketone groups take place even in the absence of oxygen, followed by the further oxidation to carboxylic acid.

In summary, nitro, nitrate, nitrite, carbonyl, and carboxyl groups may be present in the first steps of the reaction, as intermediate compounds which are finally oxidized to nitro and carboxyl groups.

Analysis of the IR spectra permits a quantitative assessment of the content of the different groups formed during the reaction as a function of degradation time. It has been reported ${ }^{8}$ that nitro and carboxyl groups are the main groups and the end product consists of methylene chains with carboxyl end groups. More recently, Rueda et al. ${ }^{17}$ analyzed the groups introduced into bulk linear and branched polyethylenes. The presence of covalent nitrate for short treatment times was described as a probable intermediary of the reaction.

Figure 1 illustrates the IR spectra for various nitric acid treatment times. As a result of the nitration reactions, several bands emerge which are related to $-\mathrm{COOH},-\mathrm{NO}_{2},-\mathrm{O}-\mathrm{NO}_{2}$ and $-\mathrm{O}-\mathrm{NO}$ groups. A quantitative analysis of the intensity of the bands. at $1710 \mathrm{~cm}^{-1}(-\mathrm{COOH}) ; 1640 \mathrm{~cm}^{-1}$

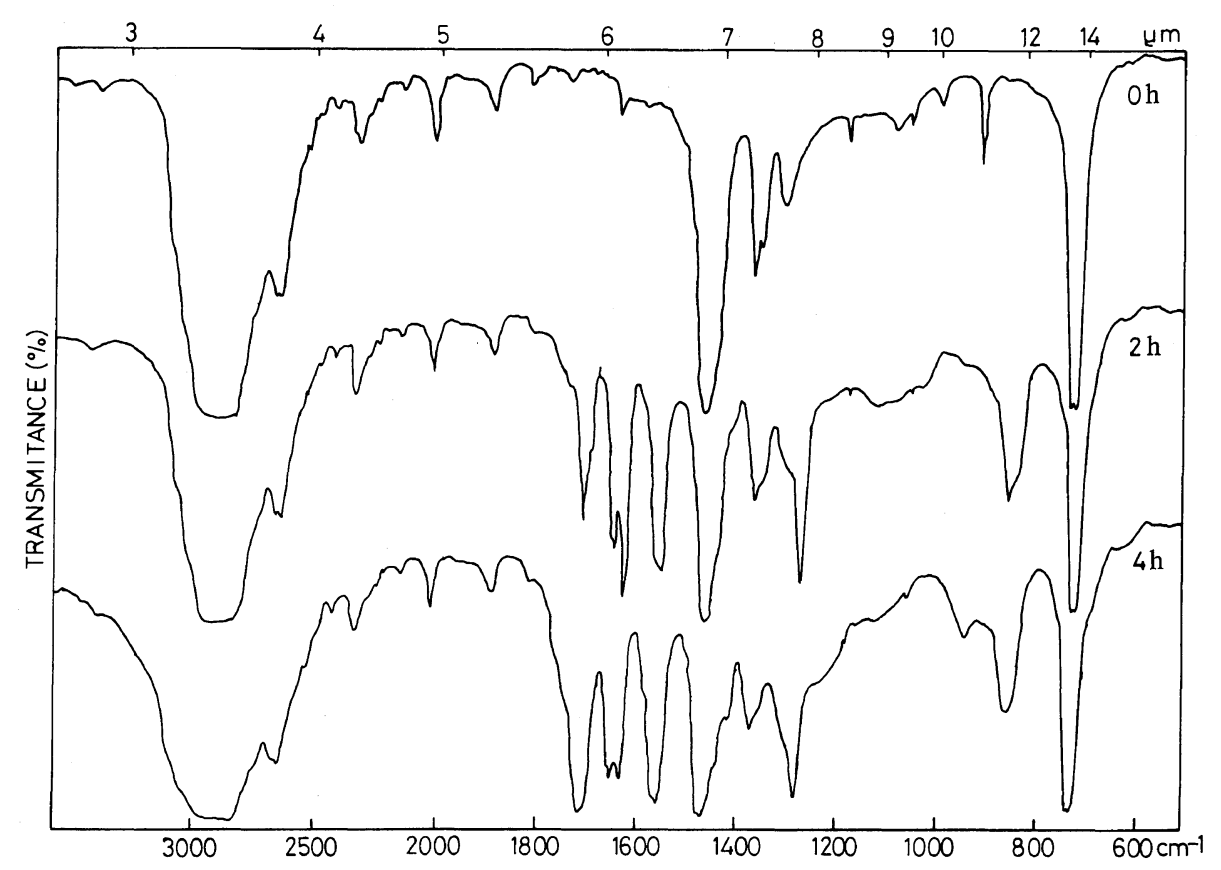

Figure 1. IR spectra of polyethylene etched by nitric acid as a function of etching time (h). 
$\left(-\mathrm{ONO}_{2}\right), 1550 \mathrm{~cm}^{-1}\left(-\mathrm{NO}_{2}\right)$, and $1650 \mathrm{~cm}^{-1}$ $(-\mathrm{ON}=\mathrm{O})$, normalized to the $-\mathrm{CH}_{2}-$ band at 1470 $\mathrm{cm}^{-1}$, was carried out at various treatment times.

The absorbance $A_{1710}$ increase with time, and the shoulder of the band may be indicative of the presence of aldehydes and ketones as oxidized intermediates. The use of carbonyl index $\left(I_{\mathrm{CO}}=\right.$

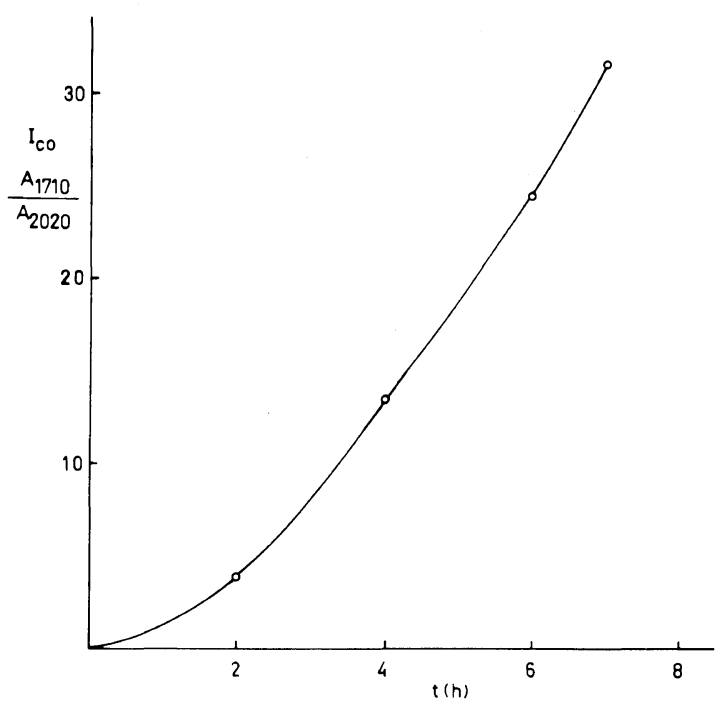

Figure 2. Carbonyl index of nitric acid treated polyethylene as a function of etching time.
$\left.E_{1710} / E_{2020}\right)$ showed that there was an exponential increase with time (Figure 2).

The presence of aldehydes could not be determined, because the aldehyde groups were in the region $2900-2700 \mathrm{~cm}^{-1}$, with corresponding bands at $975-780 \mathrm{~cm}^{-1}$. Variation in the bands, $v-\mathrm{OH}$ in acids, at $3300-2500 \mathrm{~cm}^{-1}$ and out of plane $\delta-\mathrm{OH}$, at $940 \mathrm{~cm}^{-1}$, shows that the band width increased with time.

The nitro groups may be analyzed by means of the band at $1550 \mathrm{~cm}^{-1}$. The reaction shows a sudden increase in band intensity, reaching a constant value at $6 \mathrm{~h}$. The band at $1370 \mathrm{~cm}^{-1}$, due to the symmetrical vibrational mode, may be possibly be related to the weaker intensity.

The relative content of carboxyl and nitro groups is shown in Figure 3 and the quotient increases quite rapidly in the early stages of the reaction. The quotient $A_{1710} / A_{1550}$ is multiplied by 1.4 , the ratio of the absorption coefficient of nitro to carboxyl groups. ${ }^{8}$ However, Rueda et al. ${ }^{17}$ indicated that the quotient remains practically constant at a value of 4 , for samples treated in open tubes.

Covalent nitrate groups were indicated bands at $1640 \mathrm{~cm}^{-1}\left(v_{\mathrm{s}} \mathrm{N}=\mathrm{O}\right), 1270 \mathrm{~cm}^{-1}\left(v_{\mathrm{a}} \mathrm{N}=\mathrm{O}\right)$ and $860 \mathrm{~cm}^{-1}(v-\mathrm{N}-\mathrm{O}-)$. The band at $1650 \mathrm{~cm}^{-1}$ was quite conspicuous at the very beginning of the reaction $(2-4 \mathrm{~h})$ but practically disappeared after

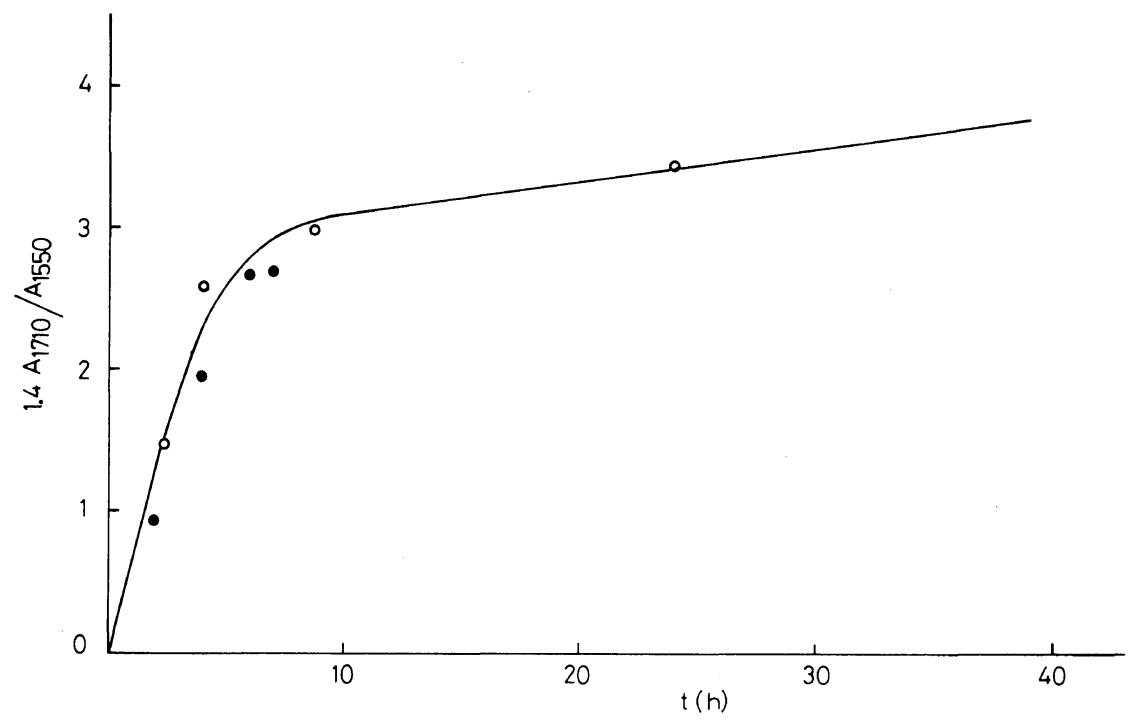

Figure 3. Relative IR absorbances of carboxyl $\left(1710 \mathrm{~cm}^{-1}\right)$ and nitro $\left(1550 \mathrm{~cm}^{-1}\right)$ bands of nitric acid treated polyethylene as a function of etching time. 1.4 is the ratio between the absorbance coefficients of the bands. 
Table I. Melting temperatures $\left({ }^{\circ} \mathrm{C}\right)$ and enthalpies $\left(\mathrm{cal} \mathrm{g}^{-1}\right)$ of polyethylene filaments $\left(M_{n}=1.34 \times 10^{5}, M_{w} / M_{n}=8.5\right)$ treated with nitric acid for various periods of time. Each filament of a different draw ratio, $\lambda$, was scanned for two consecutive runs

\begin{tabular}{|c|c|c|c|c|c|c|c|c|c|}
\hline & & \multicolumn{8}{|c|}{ Etching time/hours } \\
\hline \multicolumn{2}{|c|}{$\lambda$} & \multicolumn{2}{|c|}{0} & \multicolumn{2}{|c|}{4} & \multicolumn{2}{|c|}{6} & \multicolumn{2}{|c|}{8} \\
\hline & & $\Delta H_{\mathrm{u}}$ & $T_{\mathrm{m}}$ & $\Delta H_{\mathrm{u}}$ & $T_{\mathrm{m}}$ & $\Delta H_{\mathrm{u}}$ & $T_{\mathrm{m}}$ & $\Delta H_{\mathrm{u}}$ & $T_{\mathrm{m}}$ \\
\hline \multirow[t]{2}{*}{$1: 6$} & 1 st & 42 & 133 & 44 & 133 & 38 & 131 & 38 & 130 \\
\hline & $2 \mathrm{nd}$ & 42 & 132 & 40 & 130 & 36 & 129 & 34 & 127 \\
\hline \multirow[t]{2}{*}{$1: 8$} & 1st & 44 & 133 & 44 & 132 & 37 & 132 & 42 & 131 \\
\hline & 2nd & 44 & 132 & 40 & 129 & 34 & 129 & 37 & 128 \\
\hline \multirow[t]{2}{*}{$1: 10$} & 1st & 48 & 135 & 44 & 133 & 40 & 134 & 43 & 132 \\
\hline & 2nd & 43 & 131 & 38 & 129 & 35 & 130 & 39 & 129 \\
\hline
\end{tabular}

$6 \mathrm{~h}$ of treatment. The presence of covalent nitrate groups was first reported by Rueda et al. ${ }^{17}$

The presence of nitrite groups, reported in this work for the first time, is related to the band at $1650 \mathrm{~cm}^{-1}$ which appears only at the initiation of the reaction and practically vanishes after $4 \mathrm{~h}$ of treatment; it overlaps with the $1640 \mathrm{~cm}^{-1}$ band due to presence of groups. Nitrates and nitrites are intermediate in the reaction and are hardly present after longer periods treatment. Thus only carboxyl and nitro groups have been reported in previous studies. Nitro groups are usually always present and at higher extensions of the reaction carboxyl groups, become the end groups when the folds and the molecules come out on the crystal basal surface.

\section{Thermal Properties}

Calorimetric measurement showed that the fundamental parameters $T_{\mathrm{m}}$ and $\Delta H_{\mathrm{u}}$ do not significantly change with the short treatment times used in this work.

When the original and treated samples were analyzed, the first run yielded a single melting peak with a maximun which changed from 133 to $135^{\circ} \mathrm{C}$, depending on the draw ratio of the original sample. This peak remained the same even after $4 \mathrm{~h}$ of nitration; after $8 \mathrm{~h}$ there was a slight change, from 130 to $132^{\circ} \mathrm{C}$.

After remelting the samples, only one peak was found on the calorimetric curves, although lower $T_{\mathrm{m}}$ and broader melting curves were obtained (Table I).
This is in contrast to the reported behaviour of drawn samples after longer treatment times ${ }^{10}$ : two peaks were found, as a result of different molecular weight components produced in the samples by etching.

Moreover, the apparent melting enthalpies, determined by calorimetry, changed for the untreated samples from 42 to $48 \mathrm{cal} \mathrm{g}^{-1}$, depending on the draw ratio. Slightly lower values for $\Delta H_{\mathrm{u}}$ were found in treated samples after $8 \mathrm{~h}$ (Table I).

Under the more favorable conditions, a draw ratio of 10 and a treatment time of $8 \mathrm{~h}$, the density changed from 0.956 to $0.961 \mathrm{~g} \mathrm{~cm}^{-3}$. The constant value of $T_{\mathrm{m}}$ indicates, according to the relation ${ }^{18}$

$$
T_{\mathrm{e}}=T_{\mathrm{m}}^{\mathrm{o}}\left(1-\frac{2 \sigma_{\mathrm{e}}}{\Delta H_{\mathrm{u}} \cdot l}\right)
$$

that the quotient $\sigma_{\mathrm{e}} / l$ hardly changes with etching.

On the base of the above experimental data, it may be that at the early stages of nitration of drawn polyethylene, chemical attack occurs in a preferential and selective way on the amorphous layers, without a significant decrease in weight or molecular weight loss. With increasing draw ratio, the lesser part of the chains fold back and the larger part of the chains traverse the amorphous areas. These interconnecting chains, taut tie chains, are preferentially attacked by nitric acid at the initiation of the reaction and as long as the reaction continues, the loose layers and folds in the amorphous regions become degraded. At this point, weight and molecular loss becomes evident. 
Table II. $\alpha$ Relaxation temperatures and activation energies of different polyethylene samples.

A), original; B), annealed at $120^{\circ} \mathrm{C}$; C), nitric acid etched for $6 \mathrm{~h}$;

D), annealed after nitric acid etching.

\begin{tabular}{|c|c|c|c|c|c|}
\hline \multirow{2}{*}{ Samples- } & \multicolumn{2}{|c|}{$110 \mathrm{~Hz}$} & \multicolumn{2}{|c|}{$3,5 \mathrm{~Hz}$} & \multirow{2}{*}{$\frac{\Delta H}{\mathrm{kcal} \mathrm{mol}^{-1}}$} \\
\hline & $T /{ }^{\circ} \mathrm{C}$ & $E^{\prime \prime} / \mathrm{GPa}$ & $T /{ }^{\circ} \mathrm{C}$ & $E^{\prime \prime} / \mathrm{GPa}$ & \\
\hline A & 63 & 0.39 & 33 & 0.38 & $24 \pm 2$ \\
\hline B & 70 & 0.27 & 44 & & $26 \pm 2$ \\
\hline $\mathrm{C}$ & 61 & 0.30 & 35 & 0.38 & $28 \pm 2$ \\
\hline $\mathrm{D}$ & 66 & 0.29 & 38 & 0.27 & $25 \pm 2$ \\
\hline
\end{tabular}

Table III. $\gamma$ Relaxation temperatures and activation energies of different polyethylene samples.

Captions as referred to in Table II

\begin{tabular}{|c|c|c|c|c|c|}
\hline \multirow{2}{*}{ Samples } & \multicolumn{2}{|c|}{$110 \mathrm{~Hz}$} & \multicolumn{2}{|c|}{$3,5 \mathrm{~Hz}$} & \multirow{2}{*}{$\frac{\Delta H}{\mathrm{kcal} \mathrm{mol}^{-1}}$} \\
\hline & $T /{ }^{\circ} \mathrm{C}$ & $E^{\prime \prime} / \mathrm{GPa}$ & $T /{ }^{\circ} \mathrm{C}$ & $E^{\prime \prime} / \mathrm{GPa}$ & \\
\hline A & -122 & 0.66 & -130 & 0.36 & $18 \pm 3$ \\
\hline $\mathrm{C}$ & -123 & 0.59 & -131 & 0.36 & $18 \pm 3$ \\
\hline
\end{tabular}

\section{Dynamic Mechanical Behaviour}

By plotting the part of the complex modulus lost as a function of temperature, the two main relaxations of linear-polyethylene become apparent. The temperature and frequency of the relaxation maximum are related by the Arrhenius equation as,

$$
f=f_{0} \exp (-\Delta H / R T)
$$

where $\Delta H$ is the activation energy of the corresponding process, as listed in Tables II and III. The absolute errors of $\Delta H$ were calculated assuming a maximum variation of $\pm 1^{\circ} \mathrm{C}$ in the temperature seems unnecessary from the loss modulustemperature plot.

Table III shows that the $\gamma$ relaxation, due to crankshaft movements of methylenic sequences, is not affected by nitric acid treatment. On the other hand, the $\alpha$ relaxation temperature is affected by annealing and acid treatment but its activation energy remains almost unchanged. We consider this relaxation, according to the symmetrical shape of the $\alpha$ maxima, as a single process, as is confirmed by the constant value of the maximum loss modulus at the $\alpha$ relaxation temperature. These two conditions were not fullfilled in earlier attempts to decompose the $\alpha$ relaxation into two processes with different activation energies.

As it has shown in other works, ${ }^{19,20}$ the $\alpha$ relaxation temperature of drawn polyethylene increases about ten degrees by following the thermal history imposed in Rheovibron measurements (from 20 to $120^{\circ} \mathrm{C}$ in about $100 \mathrm{~min}$ ). Table II shows that nitric acid treatment does not change the features of the $\alpha$ relaxation and that annealing in the Rheovibron chamber of etched filaments increases the $\alpha$ relaxation temperature by $5^{\circ} \mathrm{C}$ without affecting its activation energy.

In order to clarify the present discussion of the dynamic mechanical results obtained we assembled the values of moduli at different temperatures corresponding to five series of measurements on original filament, filament previously annealed in Rheovibron chamber, nitric acid etched filament and this last filament annealed in two consecutive runs. These values show that moduli decrease both by annealing and by nitric acid treatment and that successive Rheovibron measurements do not change the moduli of nitric acid treated and annealed sample. A similar conclusion was reached for filaments annealed in Rheovibron several times. ${ }^{20}$

The decrease in modulus takes place throughout the whole range of temperature studied, and is produced to the same degree by either annealing or etching. Annealing close to melting leads to mobilization of tie molecules and consequently, decreases the elastic moduli. This also occurs by nitric acid treatment, as discussed in the next paragraph.

\section{Shrinkage Stress Measurements}

Drawn polymers heated at temperatures near the melting point develope shrinkage forces which give place to macroscopic contraction of the sample. As Keller pointed out, ${ }^{21}$ this contraction does not take place when a sample has been obtained in the extended state.

When drawn polymers are heated with their ends fixed so as to prevent macroscopic contraction, shrinkage stress is produced by taut tie molecules. ${ }^{22}$ These tie molecules are preferentially attacked by nitric acid and the attack continues for a period of a few hours. It can be seen from Figure 4 that annealing for one hour leads to a decrease in shrinkage stress similar to that produced by nitric 


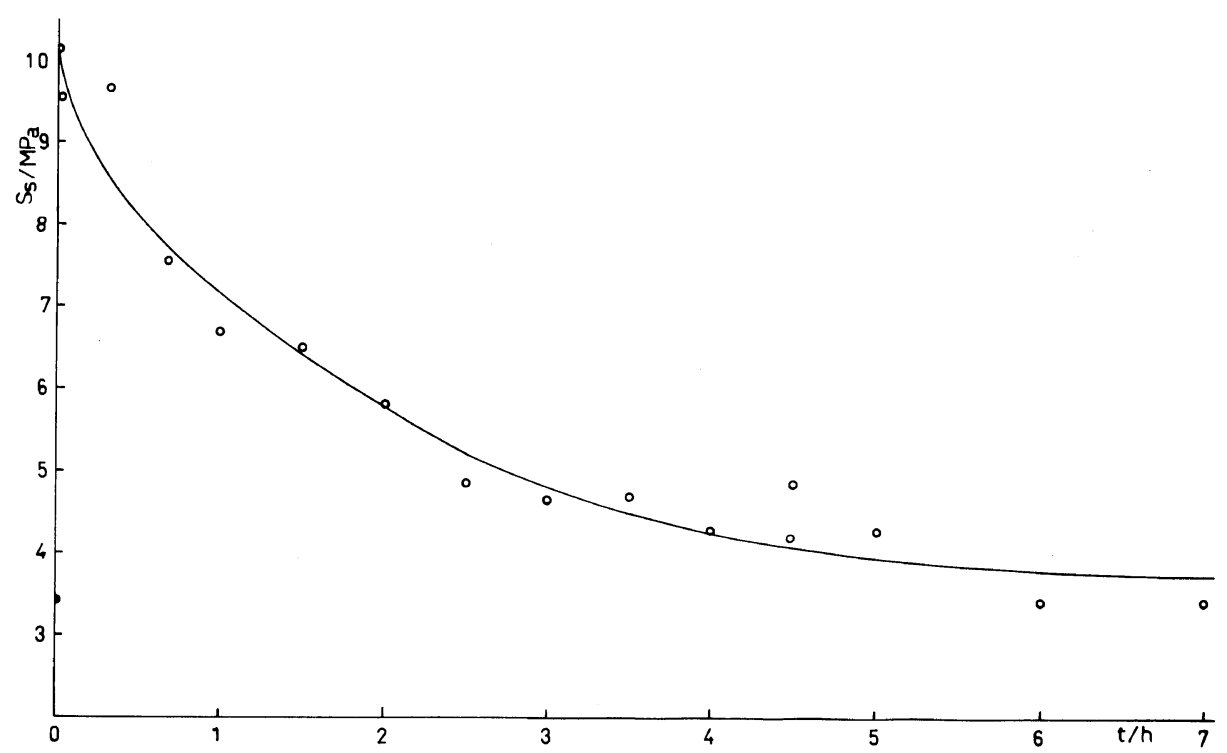

Figure 4. Maximum shrinkage stress of drawn polyethylene $(\lambda=10)$ as a function of nitric acid etching time. The filled point corresponds to a filament annealed at a temperature the same as that of the shrinkage stress measurements $\left(120^{\circ} \mathrm{C}\right)$.

acid etching over a period of seven hours. This confirms the results on viscoelastic measurements, showing that both annealing and etching diminish the values of the elastic moduli of polyethylene filaments.

Acknowledgement. The financial support of the Comision Asesora de Investigación Científica y Técnica is gratefully acknowledged.

\section{REFERENCES}

1. R. P. Palmer and A. J. Cobbold, Makromol. Chem., 74, 174 (1964).

2. A. Keller and S. Sawada, Makromol. Chem., 74, 190 (1964).

3. A. Peterlin and G. Meinel, J. Polym. Sci., B, 3, 1059 (1965).

4. A. Peterlin, G. Meinel, and H. G. Olf, J. Polym. Sci., B, 4, 399 (1966).

5. D. J. Blundell, A. Keller, and T. M. Connor, J. Polym. Sci., A-2, 6, 387 (1967).

6. T. Willians, D. J. Blundell, A. Keller, and I. M. Ward, J. Polym. Sci., A-2, 6, 1613 (1968).

7. K. H. Illers, Makromol. Chem., 118, 88 (1968).

8. A. Keller and Y. Udagawa, J. Polym. Sci., A-2, 9,
1793 (1971).

9. G. Meinel and A. Peterlin, J. Polym. Sci., Polym. Lett., 5, 197 (1967).

10. G. Meinel and A. Peterlin, J. Polym. Sci., A-2, 6, 387 (1968).

11. G. Capaccio and I. M. Ward, J. Polym. Sci., Polym. Phys. Ed., 19, 667 (1981).

12. A. Peterlin, J. Polym. Sci., C, 9, 61 (1965).

13. P. J. Flory, A. Ciferri, and R. Chiang, J. Am. Chem. Soc., 83, 1023 (1961).

14. P. S. Francis, R. Cooke, Jr., and J. H. Elliot, J. Polym. Sci., 31, 453 (1957).

15. J. M. Pereña, R. A. Duckett, and I. M. Ward, J. Appl. Polym. Sci., 25, 1381 (1980).

16. A. I. Titov and N. V. Shchitov, Dokl. Akad. Nauk. S.S.S.R., 81, 1085 (1951).

17. D. R. Rueda, E. Cagiao, and F. J. Baltá, Makromol. Chem., 182, (1981).

18. L. Mandelkern, Prog. Polym. Sci., 2, 165 (1970).

19. J. M. Pereña and J. M. G. Fatou, Anales de Física, 70, 348 (1974).

20. J. M. Pereña, J. M. G. Fatou, and R. Benavente, $J$. Appl. Polym. Sci., 27, 687 (1982).

21. P. Barham and A. Keller, J. Polym. Sci., Polym. Lett. Ed., 13, 197 (1975).

22. A. Peterlin, J. Appl. Phys., 48, 4099 (1977). 